\title{
The short-term impact of methylprednisolone on patient-reported sleep in patients with advanced cancer in a randomized, placebo-controlled, double-blind trial
}

\author{
Gunnhild Jakobsen $^{1,2}$ (D) Morten Engstrøm ${ }^{3,4}$ - Marianne Jensen Hjermstad ${ }^{5,6,7}$. Jan Henrik Rosland ${ }^{8,9}$ • \\ Nina Aass ${ }^{5,10}$. Eva Albert ${ }^{11}$ - Stein Kaasa ${ }^{1,6,7}$ - Peter Fayers ${ }^{12}$ - Pål Klepstad ${ }^{13,14}$ - Ørnulf Paulsen ${ }^{6,7,15}$
}

Received: 3 April 2020 / Accepted: 19 August 2020 / Published online: 27 August 2020

(C) The Author(s) 2020

\begin{abstract}
Purpose Although corticosteroids are frequently used in patients with advanced cancer, few studies have examined the impact of these drugs on patient-reported sleep. We aimed to examine the short-term impact of methylprednisolone on patient-reported sleep in patients with advanced cancer.

Methods Patient-reported sleep was a predefined secondary outcome in a prospective, randomized, placebo-controlled, doubleblind trial that evaluated the analgesic efficacy of corticosteroids in advanced cancer patients (18+), using opioids, and having pain $\geq 4$ past $24 \mathrm{~h}$ (NRS $0-10)$. Patients were randomized to the methylprednisolone group with methylprednisolone 16 mg $\times 2 /$ day or placebo for 7 days. The EORTC QLQ-C30 (0-100) and the Pittsburgh Sleep Quality Index questionnaire (PSQI) (0-21) were used to assess the impact of corticosteroids on sleep at baseline and at day 7.

Results Fifty patients were randomized of which 25 were analyzed in the intervention group and 22 in the control group. Mean age was 64 years, mean Karnofsky performance status was 67 (SD 13.3), 51\% were female, and the mean oral daily morphine equivalent dose was $223 \mathrm{mg}$ (SD 222.77). Mean QLQ-C30 sleep score at baseline was 29.0 (SD 36.7) in the methylprednisolone group and 24.2 (SD 27.6) in the placebo group. At day 7, there was no difference between the groups on QLQ-C30 sleep score (methylprednisolone 20.3 (SD 32.9); placebo 28.8 (SD 33.0), $p=0.173$ ). PSQI showed similar results.

Conclusions Methylprednisolone $16 \mathrm{mg}$ twice daily for 7 days had no impact on patient-reported sleep in this cohort of patients with advanced cancer.
\end{abstract}

Trial registration Clinical trial information NCT00676936 (13.05.2008)

Keywords Corticosteroids $\cdot$ Sleep $\cdot$ Advanced cancer $\cdot$ Randomized controlled trial

Gunnhild Jakobsen

gunnhild.jakobsen@ntnu.no

Morten Engstrøm

morten.engstrom@ntnu.no

Marianne Jensen Hjermstad

mariajhj@medisin.uio.no

Jan Henrik Rosland

jan.henrik.rosland@haraldsplass.no

Nina Aass

NAA@ous-hf.no

\author{
Eva Albert \\ Eva.Albert@sshf.no \\ Stein Kaasa \\ stein.kaasa@medisin.uio.no \\ Peter Fayers \\ p.fayers@abdn.ac.uk \\ Pål Klepstad \\ pal.klepstad@ntnu.no \\ Ørnulf Paulsen \\ paor@sthf.no
}

Extended author information available on the last page of the article 


\section{Background}

Patients with advanced cancer often report poor sleep quality with a prevalence that varies from 40 to $96 \%$ across studies [1-6]. The cancer disease and the cancer treatments are factors that probably contribute to sleep disturbances [7]. Treatment with corticosteroids may be a precipitating factor involved in the development of insomnia in patients with cancer [8-11]. Corticosteroids are associated with a variety of adverse effects in which sleep disturbance is one of the short-term effects [12-15]. These drugs are frequently administered to patients with advanced cancer [16-21], but usage varies between countries. For instance, a cross-sectional study of European cancer patients using opioids showed that $34 \%$ in Germany, $49 \%$ in Norway, and $72 \%$ of patients in Italy were using corticosteroids [22]. The indications for corticosteroid use in patients with advanced cancer are wide, including alleviation of distressing symptoms such as pain, anorexia, fatigue, and dyspnea as well as improving quality of life and sense of wellbeing $[16,17,20,21]$. Some patients also use corticosteroids as a part of anti-cancer therapy or for other medical conditions.

Few studies have examined the impact of corticosteroids on patient-reported sleep in patients with advanced cancer. Mercadante et al. demonstrated an inverse relation between the use of corticosteroids and sleep assessed by the Athens Insomnia Scale in patients with advanced cancer [23]. However, due to the cross-sectional design, causality between corticosteroids and sleep quality could not be assessed. Second, in a prospective survey on the use of dexamethasone in in and outpatients with advanced malignant disease, Hardy et al. demonstrated that mild sleep disturbance was reported by $17 \%$ of the patients after start of corticosteroid treatment [24]. In another study, Hatano et al. demonstrated that 19\% of patients with advanced cancer experienced sleep disturbance 1 week after start of dexamethasone given for anorexia [25]. In the latter study, sleep was rated by healthcare workers according to the National Cancer Institute's Common Toxicity Criteria for Adverse Events Likert scales. However, as sleep disturbance was not assessed by patient-reported outcome measures, it is likely underestimated. Furthermore, none of these studies used standardized doses of corticosteroids nor did they include a control group. Finally, Yennurajalingam et al. performed a randomized, double-blind, placebocontrolled study on the use of dexamethasone $4 \mathrm{mg}$ orally twice daily for 14 days for cancer-related fatigue in patients with advanced cancer. They found no difference in sleep using a numeric scale (NRS), ( 0 , no symptoms; 10 , worst possible severity) between dexamethasone and placebo at day 15 [26].

To summarize, few studies have examined the impact of standardized doses of corticosteroids on sleep by a longitudinal randomized controlled design in patients with advanced cancer. Given the high prevalence of both sleep disturbances and corticosteroid use in patients with advanced cancer, it is essential to know whether corticosteroids aggravate sleep in these patients. The aim of this study was to investigate patient-reported sleep, a predefined secondary outcome in the randomized Corticosteroids for Cancer Pain Trial (NCT00676936) [27].

\section{Methods}

\section{Overall design and participants}

The randomized Corticosteroid for Cancer Pain Trial [27] investigated the analgesic effect of methylprednisolone on pain, with patient-reported sleep as a predefined secondary outcome in a prospective, randomized, placebo-controlled, doubleblind design [27]. Eligible patients in the randomized controlled trial had verified malignant disease, aged 18 years or above, self-reported average pain $\geq 4$ last $24 \mathrm{~h}$ (assessed on a Numerical Rating Scale (NRS) 0-10), used opioids for moderate or severe cancer pain, and had an expected length of survival of more than 4 weeks. Exclusion criteria were severe pain, defined as 8 or above on the NRS last $24 \mathrm{~h}$; regular corticosteroid use; initiated radiotherapy or systematic cancer treatment in the past 4 weeks; diagnosed with diabetes mellitus, peptic ulcer disease, spinal cord compression, or being in need of bone surgery; and ongoing treatment with nonsteroidal anti-inflammatory drugs. Patients with obvious cognitive impairment as judged by the treating physician according to standard criteria (e.g., confusion, disorientation, low attention span and incoherent speech) were also not eligible [27]. Five palliative care and outpatient oncology services in Norway participated in the study [27].

\section{Study treatment}

Patients were randomized to methylprednisolone $16 \mathrm{mg}$ or placebo twice daily for 7 days. The study drug was administered in the morning and before 6 p.m. in the afternoon. Patients and members of the research team were all blinded to treatment assignment throughout the study. Details of the study procedures are described in the original article [27].

\section{Outcome measures}

\section{Sleep}

Sleep, a secondary outcome predefined in the protocol [27], was assessed at baseline and day 7 using the European Organization for Research and Treatment of Cancer Quality of Life Questionnaire Core 30 (QLQ-C30) [28]. The QLQC30 includes a single question assessing sleep difficulty: "(During the past week) Have you had trouble sleeping?" The QLQ-C30 sleep item has four response categories from "not at all" to "very much". The raw scores are transformed 
linearly to a scale from 0 to 100 , i.e., QLQ-C30 sleep score, where a high score represents more sleeping trouble [28]. A mean difference of 10-20 points is described as a moderate change that is perceptible to patients [29]. Thus, a difference of 15 points on the QLQ-C30 sleep score was considered clinically significant in this trial.

Sleep quality was also assessed by the Pittsburgh Sleep Quality Index questionnaire (PSQI) [30]. The PSQI is a 19item self-report questionnaire that assesses sleep quality. The recall period is 1 month. The questionnaire comprises seven domains: subjective sleep quality, sleep latency, sleep duration, normal sleep efficiency, sleep disturbances, the application of sleep medicine, and daytime dysfunction [30]. Each domain has a response score ranging from 0 to 3 , with lower scores indicating better sleep quality. The seven component scores are summed to yield a PSQI total global score (0-21). PSQI total global scores $>5$ indicate poor sleep $[4,30]$.

Cognitive function was assessed pre- and posttreatment by the Mini Mental State Exam (MMSE). The MMSE has 20 items and a sum score of 30 points [31]. Performance status was rated by the Karnofsky performance status (KPS) [32]. Patients reported their daily analgesic consumption, and opioid dosages were converted to oral morphine equivalents [33].

\section{Statistical analysis}

Power calculations were presented in the original article and were based on the primary outcome of average pain intensity measured at day 7 (on an NRS 0-10 $(0=$ no pain, $10=$ worst imaginable pain) [27]. The estimated sample size was 22 evaluable patients in each group.

Demographic variables are reported as means with standard deviation (SD) or frequencies. The main sleep outcome was the QLQ-C30 sleep score day 7 after treatment. Difference between the intervention group and the control group in QLQ-C30 sleep score on day 7 was assessed using a general linear model (ANCOVA) including baseline values as a covariate in the model. We also calculated the change score for each patient by subtracting the baseline sleep score (day 0) from the score at end of treatment (day 7).

Differences between the two groups were also assessed in explorative analyses using the global PSQI score and each of the PSQI dimensions as the dependent variable in the ANCOVA model, i.e., subjective sleep quality, sleep latency, sleep duration, sleep efficiency, sleep disturbances, sleep medication, and dysfunction (0-3), and the patient-reported sleep onset latency in minutes. The baseline value was in each case used as a covariate in the model.

There was one missing item in the PSQI-sleep disturbance scale in the PSQI. This was imputed by the last observation carried forward. One patient had a missing value in the QLQC30 sleep item at baseline, and one patient had a missing value at day 7 ; no imputation method was used, as these were single items.

A two-sided $P$ value of $<0.05$ was considered statistically significant. $P$ values were not adjusted for multiple testing. SPSS statistical software (version 25.0) was used.

\section{Results}

\section{Study population}

Fifty patients were randomized to methylprednisolone $16 \mathrm{mg}$ twice daily or placebo, 26 were allocated to the methylprednisolone group and 24 to the placebo group, of which 25 could be evaluated in the methylprednisolone group and 22 in the placebo group (Fig. 1). Figure 1 reports the essentials for analysis of sleep and is adapted from the diagram in the original trial [27].

The overall mean age of patients was 64.1 years (SD 10.1), mean Karnofsky performance status was 67.1 (SD 13.3), 51\% were female, and the mean opioid dose was $223 \mathrm{mg}$ (SD 223). Table 1 shows baseline demographics and clinical characteristics for each treatment group.

\section{Patient-reported sleep}

The mean QLQ-C30 sleep score at baseline was 29.0 (SD $36.7)$ in the methylprednisolone group $(n=23)$ and 24.2 (SD $27.6)$ in the placebo group $(n=22)$. At day 7 , after controlling for pre-intervention scores on sleep, there were neither any clinical nor any statistically significant differences in the QLQ-C30 sleep score with methylprednisolone compared with placebo (ANCOVA, $\mathrm{F}=1.92, p=0.173$ ) (Table 2; Fig. 2). The mean change in the QLQ-C30 sleep score was -8.7 (SD 25.1) in the methylprednisolone group and 4.6 (SD 34.6) in the placebo group.

At baseline, the mean PSQI global score was 8.2 (SD 4.3) and 7.6 (SD 3.7) in the methylprednisolone $(n=25)$ and placebo $(n=22)$ groups, respectively. At baseline, 18 of $25(72 \%)$ of the patients in the methylprednisolone group and 15 of 22 $(68 \%)$ in the placebo group were categorized as poor sleepers (PSQI global score $>5$ ). At day 7, there were no significant differences between the groups in the global PSQI score ( $p=$ 0.809) or any of the single PSQI dimensions (Table 2).

\section{Discussion}

The main finding of this trial was that treatment with methylprednisolone $16 \mathrm{mg}$ twice daily for 7 days in patients with advanced cancer did not result in more patient-reported sleep problems as measured by the QLQ-C30 sleep score and the PSQI. 
Fig. 1 CONSORT flow diagram of the progress through the phases of the trial. The figure reports the essentials for analysis of sleep and is adapted from the diagram in the original trial [27]

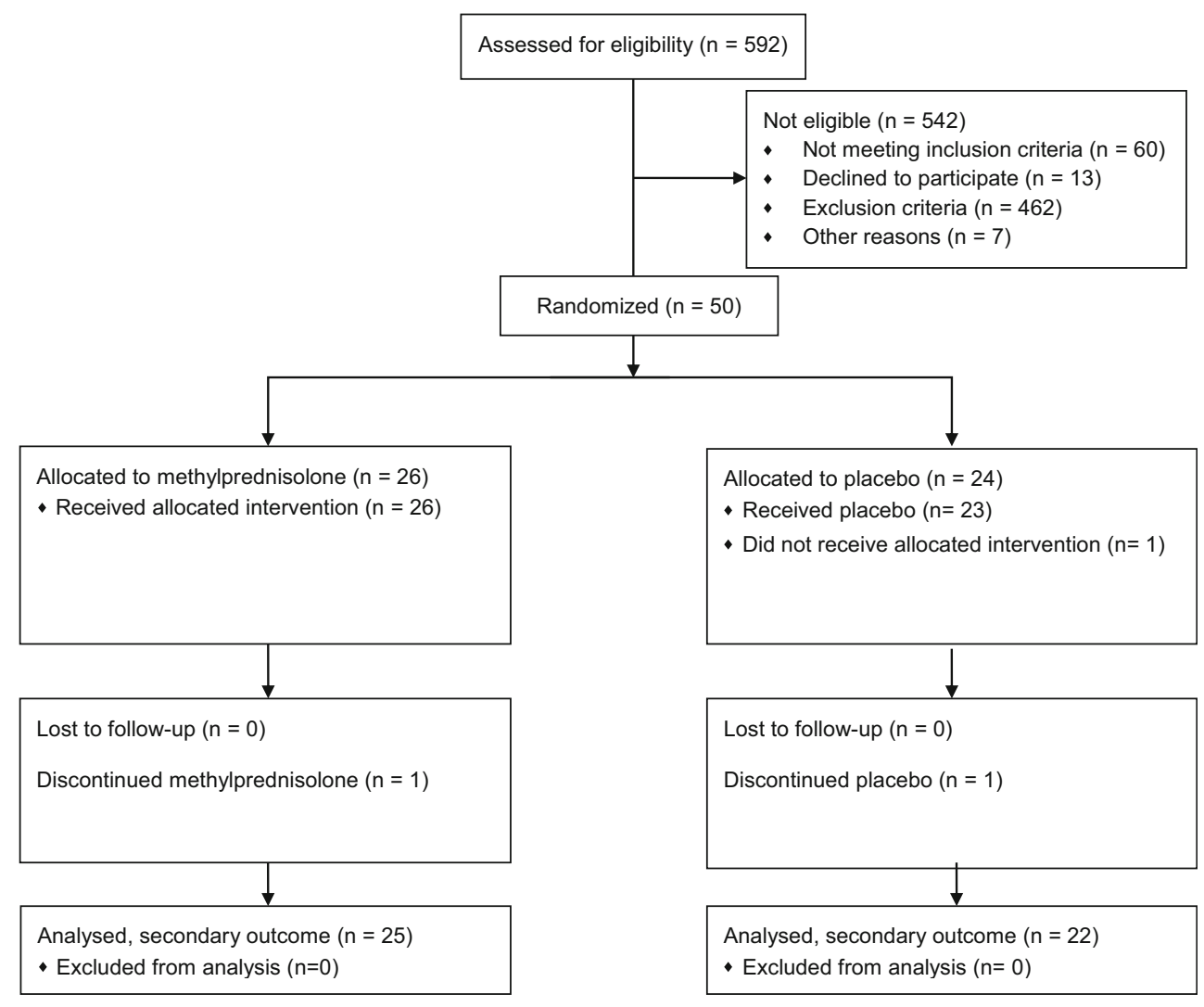

Table 1 Demographic and clinical characteristics at inclusion

\begin{tabular}{|c|c|c|}
\hline Characteristics & Methylprednisolone $(n=25)$ & Placebo $(n=22)$ \\
\hline Age (years), mean (SD) & $62.5(8.6)$ & $66.0(11.3)$ \\
\hline \multicolumn{3}{|l|}{ Gender, $n(\%)$} \\
\hline Female & $13(52)$ & $11(50)$ \\
\hline Male & $12(48)$ & $11(50)$ \\
\hline Body mass index $\left(\mathrm{kg} / \mathrm{m}^{2}\right)$, mean (SD) & $24.2(5.8)$ & $21.7(3.4)$ \\
\hline \multicolumn{3}{|l|}{ Cancer diagnosis, $n(\%)$} \\
\hline Breast & $1(4)$ & $1(5)$ \\
\hline Prostate & $2(8)$ & $3(14)$ \\
\hline Gastrointestinal & $6(24)$ & $5(23)$ \\
\hline Lung & $6(24)$ & $5(23)$ \\
\hline Gynecologic & $5(20)$ & $5(23)$ \\
\hline Other & $7(28)$ & $3(14)$ \\
\hline Cognitive function, (MMSE), mean & 27.1 & 27.0 \\
\hline Performance score, (KPS), mean (SD) & $66.6(14.1)$ & $65.6(13.8)$ \\
\hline \multicolumn{3}{|l|}{ Concomitant disease, $n(\%)$} \\
\hline Cardiac & $4(16)$ & $4(18)$ \\
\hline Vascular & $5(19)$ & $8(36)$ \\
\hline Lung & $3(12)$ & $4(18)$ \\
\hline Opioid analgesics, mean (SD) oral morphine equivalents ${ }^{\mathrm{a}}$ & $273.8(256.8)$ & $165.8(163.9)$ \\
\hline Mean number of other medications (SD) & $4.0(2.1)$ & $4.5(2.0)$ \\
\hline Hypnotics ${ }^{\mathrm{b}}, n(\%)$ & $9(35)$ & $6(25)$ \\
\hline Antidepressants ${ }^{\mathrm{c}}, n(\%)$ & $4(15)$ & $4(18)$ \\
\hline Benzodiazepines ${ }^{\mathrm{d}}, n(\%)$ & $3(12)$ & $6(25)$ \\
\hline
\end{tabular}

SD standard deviation, MMSE Mini-Mental State Examination [31], KPS Karnofsky Performance Score: 0 (dead) to 100 (normal activity) [32]

${ }^{\mathrm{a}} \mathrm{mg}$ per day

${ }^{\mathrm{b}}$ Hypnotics, i.e., zopiclone, nitrazepam, alimemazine

${ }^{\mathrm{c}}$ Antidepressants (citalopram, escitalopram, sertraline, mirtazapine)

${ }^{\mathrm{d}}$ Benzodiazepines (oxazepam) 
Table 2 Sleep scores at baseline and Day 7

\begin{tabular}{|c|c|c|c|c|}
\hline Variable & Baseline Mean (SD) & $\begin{array}{l}\text { Day } 7 \\
\text { Mean (SD) }\end{array}$ & $\begin{array}{l}\text { Mean change } \\
\text { D0 to D7 (SD) }\end{array}$ & $p$ value \\
\hline \multicolumn{5}{|l|}{ QLQ-C30 Sleep score ${ }^{\mathrm{b}}$} \\
\hline Methylprednisolone & $29.0(36.7)$ & $20.3(32.9)$ & $-8.7(25.1)$ & \multirow[t]{2}{*}{0.173} \\
\hline Placebo & $24.2(27.6)$ & $28.8(33.0)$ & $4.6(34.6)$ & \\
\hline \multicolumn{5}{|l|}{ PSQI, global score ${ }^{\mathrm{c}}$} \\
\hline Methylprednisolone & $8.24(4.25)$ & $8.52(5.02)$ & $0.28(2.01)$ & \multirow[t]{2}{*}{0.809} \\
\hline Placebo & $7.64(3.67)$ & $8.05(3.66)$ & $0.41(1.68)$ & \\
\hline \multicolumn{5}{|l|}{ Subjective sleep quality ${ }^{\mathrm{d}}$} \\
\hline Methylprednisolone & $1.08(0.86)$ & $0.92(0.86)$ & $-0.16(0.62)$ & \multirow[t]{2}{*}{0.305} \\
\hline Placebo & $0.95(0.79)$ & $1.0(0.82)$ & $0.05(0.58)$ & \\
\hline \multicolumn{5}{|l|}{ Sleep latency ${ }^{\mathrm{d}}$} \\
\hline Methylprednisolone & $1.20(1.04)$ & $1.24(1.05)$ & $0.04(0.79)$ & \multirow[t]{2}{*}{0.217} \\
\hline Placebo & $0.95(0.90)$ & $1.32(0.84)$ & $0.37(0.66)$ & \\
\hline \multicolumn{5}{|l|}{ Sleep duration ${ }^{\mathrm{d}}$} \\
\hline Methylprednisolone & $0.48(0.87)$ & $0.60(1.00)$ & $0.12(0.73)$ & \multirow[t]{2}{*}{0.994} \\
\hline Placebo & $0.32(0.78)$ & $0.45(0.85)$ & $0.13(0.35)$ & \\
\hline \multicolumn{5}{|c|}{ Habitual sleep efficiency ${ }^{\mathrm{d}}$} \\
\hline Methylprednisolone & $1.04(1.10)$ & $1.28(1.21)$ & $0.24(0.78)$ & \multirow[t]{2}{*}{0.704} \\
\hline Placebo & $0.82(1.05)$ & $1.00(1.20)$ & $0.18(0.66)$ & \\
\hline \multicolumn{5}{|l|}{ Sleep disturbance ${ }^{\mathrm{d}}$} \\
\hline Methylprednisolone & $1.32(0.63)$ & $1.32(0.48)$ & $0.00(0.71)$ & \multirow[t]{2}{*}{0.805} \\
\hline Placebo & $1.36(0.58)$ & $1.36(0.49)$ & $0.00(0.66)$ & \\
\hline \multicolumn{5}{|l|}{ Use of sleep medication ${ }^{\mathrm{d}}$} \\
\hline Methylprednisolone & $1.80(1.44)$ & $1.84(1.46)$ & $0.04(0.20)$ & \multirow[t]{2}{*}{0.171} \\
\hline Placebo & $1.73(1.45)$ & $1.68(1.49)$ & $-0.05(0.21)$ & \\
\hline \multicolumn{5}{|l|}{ Daytime dysfunction $^{\mathrm{d}}$} \\
\hline Methylprednisolone & $1.32(1.03)$ & $1.32(0.94)$ & $0.00(1.00)$ & \multirow[t]{2}{*}{0.414} \\
\hline Placebo & $1.50(0.96)$ & $1.23(0.87)$ & $-0.27(0.90)$ & \\
\hline \multicolumn{5}{|l|}{ Sleep onset latency, $\min ^{\mathrm{e}}$} \\
\hline Methylprednisolone & $23.7(18.8)$ & $22.5(17.6)$ & $-1.1(13.6)$ & \multirow[t]{2}{*}{0.118} \\
\hline Placebo & $30.3(39.1)$ & $32.6(36.4)$ & $3.5(11.6)$ & \\
\hline
\end{tabular}

${ }^{a} p$ value for comparison of follow up scores for the study groups (methylprednisolone and placebo) from the ANCOVA model

${ }^{\mathrm{b}}$ EORTC QLQ-C30 symptom scale (0-100) where a high score denotes higher symptom burden [28]

${ }^{\mathrm{c}}$ Pittsburg Sleep Quality Index global score 0-21, where a high score denotes more sleep problems [30]

${ }^{\mathrm{d}}$ PSQI component score $0-3$

${ }^{\mathrm{e}}$ Sleep onset latency in minutes from the PSQI

Our finding is similar to the results of a prospective, randomized, double-blind, placebo-controlled trial which primarily assessed the effects of oral dexamethasone $4 \mathrm{mg}$ twice daily on cancer-related fatigue [26]. In that study, Yennurajalingam et al. found no change in sleep scores, as measured by a NRS of 0 to 10 , in the dexamethasone group compared with the placebo group during 14 days of treatment in patients with advanced cancer. Our findings also agree with a cross-sectional study that observed no association between sleep disturbance and the use of corticosteroids in 442 advanced cancer patients in outpatient palliative care [34].
In contrast, other studies have demonstrated an association between use of corticosteroids and sleep disturbance in patients with advanced cancer. Mercadante et al. reported that use of corticosteroids was positively associated with subjective sleep disturbance [23] and was associated with significant sleep problems [19]. Moreover, insomnia was frequently reported in two prospective studies on corticosteroids for symptom control in palliative patients $[24,25]$. However, these studies are limited by lack of a comparison group and not using a standardized dose of corticosteroids. 
Fig. 2 Mean score of QLQ-C30 sleep item according to treatment arm. A higher score represents more sleeping trouble. There were no statistically significant difference in change of sleep problems between the treatment arms (error bars 95\% CI)

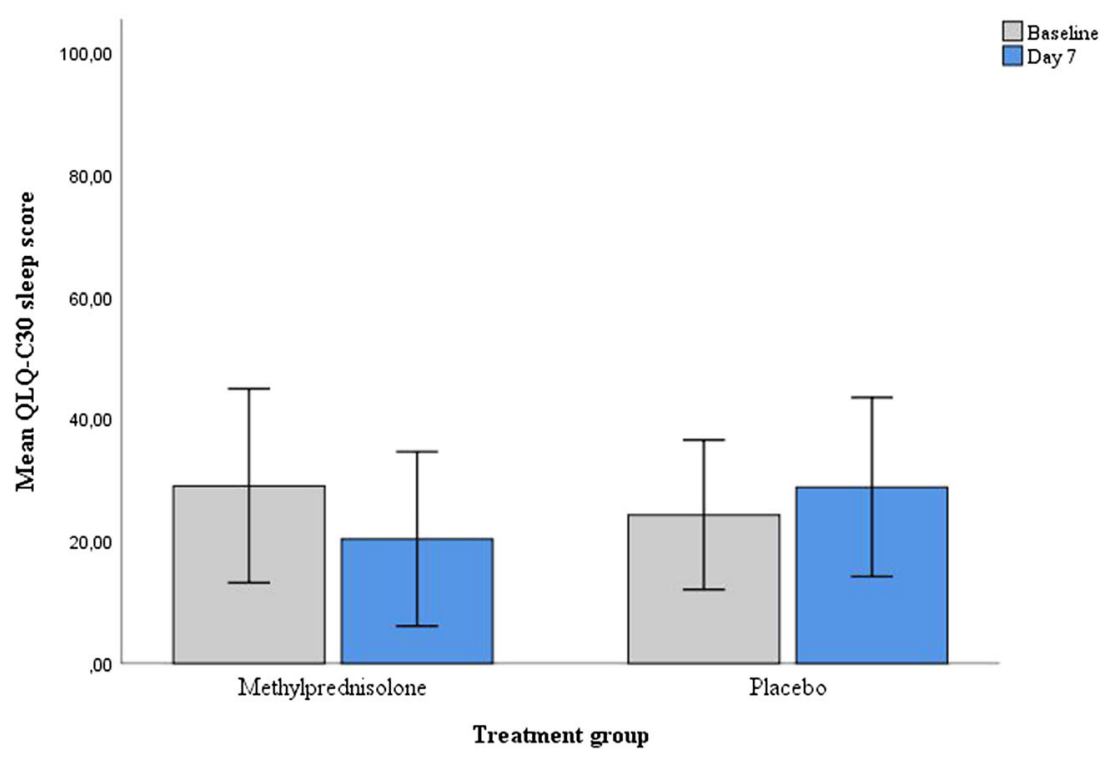

Several issues need to be addressed to interpret the findings from studies of sleep in palliative care. First, it may be difficult to differentiate corticosteroid adverse effects from symptoms related to a progressing malignant disease in patients with advanced cancer [24]. Compared to patients with less advanced disease, an isolated effect of corticosteroid use on sleep may be difficult to ascertain in patients with advanced disease who often have a higher symptom burden [35]. For instance, Chrousos et al. performed a placebo-controlled randomized trial and found that $50 \%$ of patients taking prednisolone for optic neuritis reported sleep disturbance, compared with $20 \%$ in the placebo group [36]. Additionally, corticosteroids may improve other symptoms in patients with advanced cancer which may indirectly influence sleep. In the present study, patient-reported appetite, fatigue, and patient satisfaction significantly improved in the methylprednisolone group [27]. Another example is a randomized controlled trial showing corticosteroids to be effective in improving cancer-related fatigue [26]. A qualitative study by Lundström et al. reported that corticosteroids administered for symptom control in patients with advanced metastatic cancer had positive existential consequences [37]. Moreover, studies have shown an association between the symptoms of sleep and fatigue [38, 39]. Thus, in patients with advanced cancer positive effects of corticosteroids on other symptoms that influence sleep may counter-balance potential direct negative short-term effects from corticosteroids on patient-reported sleep.

The second issue relates to the level of patient-reported sleep at baseline. In our trial, the QLQ-C30 sleep scores of 24 and $29(0-100)$ in the study groups at baseline are in line with results from other studies in advanced-cancer patients [40-42], indicating poorer sleep compared with the general population [43]. Moreover, we found that $70 \%$ of the patients reported poor sleep quality on the PSQI before study start, echoing results from other studies with prevalence of poor sleep quality from 40 to $96 \%$ in patients with advanced cancer [2-5]. Thus, poor sleep quality at baseline in our trial might explain why these patients responded differently to corticosteroids than observed in other cohorts.

The third issue relates to the dose and timing of corticosteroids. The equipotent dose of methylprednisolone $32 \mathrm{mg}$ in our trial equals about $6.4 \mathrm{mg}$ dexamethasone, which was slightly lower than the dexamethasone dose of $8 \mathrm{mg}$ in the randomized controlled trial by Yennurajalingam et al. [26]. The daily dose of corticosteroids is a risk factor for the development of sleep disturbance [15], i.e., higher doses of corticosteroids having more impact on sleep quality. Furthermore, the time of administration of corticosteroids may be an important factor for the impact on sleep. In our trial, patients were requested to take methylprednisolone in the morning and before $6 \mathrm{p} . \mathrm{m}$. in the afternoon. Additionally, methylprednisolone has a shorter half-life compared with dexamethasone. This may have prevented sleep disturbance attributed to administration of corticosteroids late in the evening.

A final issue is the duration of the present trial. Since patients with advanced cancer are frail, attrition may make a longer study duration unfeasible [44]. On the other hand, a short study will not detect long-term effects. However, a review reported that 39$86 \%$ of adverse psychiatric effects, including insomnia, occurred during the first week after start of corticosteroids [15]. Thus, we consider a duration of 7 days to be adequate to explore the shortterm impact of corticosteroids on patient-reported sleep in this cohort of patients with advanced cancer.

We recognize some limitations in this trial. First, patientreported sleep was a secondary outcome in this randomized trial. Accordingly, the initial sample size estimation and power calculations were estimated for changes in self-reported pain, not sleep. Further, the sample size was small, which is 
reflected by the wide $95 \%$ confidence intervals. However, the mean QLQ-C30 sleep score actually improved in the methylprednisolone group compared with a deterioration in the placebo group, which supports the conclusion that a deterioration due to a corticosteroid induced adverse effect in this cohort is unlikely (i.e., a type II error). Second, the recall period of PSQI of 1 month makes it less appropriate for studies with shorter intervention periods. However, in the present trial, we could not detect an impact on sleep after 7 days of intervention neither with a questionnaire using a recall period of 1 week (QLQ-C30) nor with a recall period of 1 month (PSQI). Moreover, a study that examined the ecological validity for each of the items on the PSQI reported that patients' results were comparable regardless of the length of the recall period from 3 days through a month [45]. Third, only a minor part of screened patients was eligible which leads to a risk for a selection bias. Finally, despite randomization, the corticosteroid group had slightly higher absolute levels of opioid consumption at baseline compared with the placebo group. Exploratory analysis including opioid consumption as a covariate did not change the results (data not reported). Thus, it is highly unlikely that the opioid consumption had any influence on the results.

This trial has several strengths. First, this was a randomized, placebo-controlled, double-blind trial using a standardized dosing of corticosteroids. Second, this trial recruited the predefined number of patients and had few dropouts compared with other trials in this patient group [26]. Third, the patient-reported outcomes are consistent with the previously published investigator report of adverse effects (AEs) in the present trial. The presence of adverse effects was assessed by the investigator through semi-structured interviews (presence of predefined AE category [yes vs. no] at day 7). "Sleeplessness" was noted by four participants in the methylprednisolone group as compared with three participants in the placebo group [27]. Finally, we consider these results important and relevant for clinical practice. The cohort studied represented patients with advanced cancer and a high symptom burden. As corticosteroids are commonly used, it is important to know that the use of methylprednisolone is well tolerated, also in terms of sleep.

\section{Conclusions}

In conclusion, methylprednisolone $16 \mathrm{mg}$ twice daily for 7 days had no impact on patient-reported sleep in a cohort of patients with advanced cancer treated with opioids. The majority of patients in this cohort reported poor sleep quality at baseline, emphasizing the need to address and treat sleep disturbances. The effects of long-term administration of corticosteroids on sleep in patients with advanced cancer need to be examined in a future study.
Acknowledgments The authors would like to thank the personnel at the participating centers for their contribution in recruiting patients and collecting data and patients for participating in the study.

Authors' contributions ØР, $\mathrm{PK}, \mathrm{PF}$, and SK were responsible for the conception of the study. ØP, JHR, NAa, GJ, and EA collected the data, which were analyzed, by GJ, PF, PK, and ØP. Data were interpreted by GJ, ME, MJH, PK, and ØP and confirmed by all authors. All the authors were involved in the manuscript writing and critically appraised the manuscript before providing final approval.

Funding Open Access funding provided by NTNU Norwegian University of Science and Technology (incl St. Olavs Hospital Trondheim University Hospital). The trial was supported by unrestricted grants from the Telemark Hospital Trust and the South-Eastern Norway Regional Health Authority. GJ has a grant from the Liaison Committee between the Central Norway Regional Health Authority (RHA) and the Norwegian University of Science and Technology (NTNU) (Project number 46083200).

Data availability The datasets generated and/or analyzed during the current study are available from the corresponding author on reasonable request.

\section{Compliance with ethical standards}

Disclaimer The funders had no role in the trial design, collection, analysis and interpretation of data, or writing.

Conflict of interest Marianne Jensen Hjermstad, Jan Henrik Rosland, Nina Aass, Eva Albert, Peter Fayers, and Pål Klepstad have nothing to disclose. Ørnulf Paulsen has received $\mathrm{PhD}$ grant from the Telemark Hospital Trust and the South-Eastern Norway Regional Health Authority. Gunnhild Jakobsen has received $\mathrm{PhD}$ grant from the Liaison Committee between the Central Norway Regional Health Authority (RHA) and the Norwegian University of Science and Technology (NTNU). Morten Engstrøm has received lecture fees and support for travel from ResMed and Philips. Stein Kaasa is one of the shareholders in Eir Solution $\mathrm{A} / \mathrm{S}$ and has research funding from Nutricia for other studies. The authors declare no income, dividend, or financial benefits from the work presented here.

Ethics approval and consent to participate Ethical approval was given for the primary study by the Regional Committee for Medical Research Central Norway (4.2007.846). All patients were informed about the nature of the study and provided written informed consent to participate. The study was conducted in accordance with the principles of the Declaration of Helsinki.

Code availability Not applicable.

Consent for publication Not applicable

Open Access This article is licensed under a Creative Commons Attribution 4.0 International License, which permits use, sharing, adaptation, distribution and reproduction in any medium or format, as long as you give appropriate credit to the original author(s) and the source, provide a link to the Creative Commons licence, and indicate if changes were made. The images or other third party material in this article are included in the article's Creative Commons licence, unless indicated otherwise in a credit line to the material. If material is not included in the article's Creative Commons licence and your intended use is not permitted by statutory regulation or exceeds the permitted use, you will need to obtain 
permission directly from the copyright holder. To view a copy of this licence, visit http://creativecommons.org/licenses/by/4.0/.

\section{References}

1. Otte JL, Carpenter JS, Manchanda S, Rand KL, Skaar TC, Weaver M, Chernyak Y, Zhong X, Igega C, Landis C (2015) Systematic review of sleep disorders in cancer patients: can the prevalence of sleep disorders be ascertained? Cancer medicine 4:183-200

2. Akman T, Yavuzsen T, Sevgen Z, Ellidokuz H, Yilmaz AU (2015) Evaluation of sleep disorders in cancer patients based on pittsburgh sleep quality index. Eur J Cancer Care (Engl) 24:553-559

3. Jakobsen G, Engstrom M, Fayers P, Hjermstad MJ, Kaasa S, Kloke M, Sabatowski R, Klepstad P (2019) Sleep quality with WHO Step III opioid use for cancer pain BMJ Supportive \& Palliative care 9: 307-315

4. Delgado-Guay M, Yennurajalingam S, Parsons H, Palmer JL, Bruera E (2011) Association between self-reported sleep disturbance and other symptoms in patients with advanced cancer. J Pain Symptom Manag 41:819-827

5. Mystakidou K, Parpa E, Tsilika E, Gennatas C, Galanos A, Vlahos L (2009) How is sleep quality affected by the psychological and symptom distress of advanced cancer patients? Palliat Med 23:4653

6. Yennurajalingam S, Balachandran D, Pedraza Cardozo SL, Berg EA, Chisholm GB, Reddy A, DeLa CV, Williams JL, Bruera E (2017) Patient-reported sleep disturbance in advanced cancer: frequency, predictors and screening performance of the Edmonton Symptom Assessment System sleep item. BMJ supportive \& palliative care 7:274-280

7. Chen D, Yin Z, Fang B (2018) Measurements and status of sleep quality in patients with cancers. Support Care Cancer 26:405-414

8. Savard J, Morin CM (2001) Insomnia in the context of cancer: a review of a neglected problem. J Clin Oncol 19:895-908

9. Innominato PF, Roche VP, Palesh OG, Ulusakarya A, Spiegel D, Levi FA (2014) The circadian timing system in clinical oncology. Ann Med 46:191-207

10. Twycross R (1994) The risks and benefits of corticosteroids in advanced cancer. Drug Saf 11:163-178

11. Theobald DE (2004) Cancer pain, fatigue, distress, and insomnia in cancer patients, Clin Cornerstone. 6(Suppl 1D):S15-S21

12. Poetker DM, Reh DD (2010) A comprehensive review of the adverse effects of systemic corticosteroids. Otolaryngol Clin North Am 43:753-768

13. Fietta P, Fietta P, Delsante G (2009) Central nervous system effects of natural and synthetic glucocorticoids Psychiatry Clin Neurosci 63: 613-622

14. Curtis JR, Westfall AO, Allison J, Bijlsma JW, Freeman A, George V, Kovac SH, Spettell CM, Saag KG (2006) Population-based assessment of adverse events associated with long-term glucocorticoid use. Arthritis Rheum 55:420-426

15. Warrington TP, Bostwick JM (2006) Psychiatric adverse effects of corticosteroids. Mayo Clin Proc 81:1361-1367

16. Gannon C, McNamara P (2002) A retrospective observation of corticosteroid use at the end of life in a hospice. J Pain Symptom Manag 24:328-334

17. Lundstrom SH, Furst CJ (2006) The use of corticosteroids in Swedish palliative care. Acta Oncol 45:430-437

18. Pilkey J, Streeter L, Beel A, Hiebert T, Li X (2012) Corticosteroidinduced diabetes in palliative care. J Palliat Med 15:681-689
19. Mercadante S, Adile C, Ferrera P, Masedu F, Valenti M, Aielli F (2017) Sleep disturbances in advanced cancer patients admitted to a supportive/palliative care unit. Support Care Cancer 25:1301-1306

20. Denton A, Shaw J (2014) Corticosteroid prescribing in palliative care settings: a retrospective analysis in New Zealand. BMC Palliat Care 13:7

21. Wooldridge JE, Anderson CM, Perry MC (2001) Corticosteroids in advanced cancer. Oncology (Williston Park) 15:225-234 discussion 234-226

22. Kotlinska-Lemieszek A, Paulsen O, Kaasa S, Klepstad P (2014) Polypharmacy in patients with advanced cancer and pain: a European cross-sectional study of 2282 patients. J Pain Symptom Manage 48:1145-1159

23. Mercadante S, Aielli F, Adile C, Ferrera P, Valle A, Cartoni C, Pizzuto M, Caruselli A, Parsi R, Cortegiani A, Masedu F, Valenti M, Ficorella C, Porzio G (2015) Sleep disturbances in patients with advanced cancer in different palliative care settings. J Pain Symptom Manage 50:786-792

24. Hardy JR, Rees E, Ling J, Burman R, Feuer D, Broadley K, Stone P (2001) A prospective survey of the use of dexamethasone on a palliative care unit. Palliat Med 15:3-8

25. Hatano Y, Moroni M, Wilcock A, Quinn S, Csikos A, Allan SG, Agar M, Clark K, Clayton JM, Currow DC (2016) Pharmacovigilance in hospice/palliative care: the net immediate and short-term effects of dexamethasone for anorexia BMJ supportive \& palliative care 6: $331-337$

26. Yennurajalingam S, Frisbee-Hume S, Palmer JL, Delgado-Guay MO, Bull J, Phan AT, Tannir NM, Litton JK, Reddy A, Hui D, Dalal S, Massie L, Reddy SK, Bruera E (2013) Reduction of cancer-related fatigue with dexamethasone: a double-blind, randomized, placebo-controlled trial in patients with advanced cancer. J Clin Oncol 31:3076-3082

27. Paulsen O, Klepstad P, Rosland JH, Aass N, Albert E, Fayers P, Kaasa S (2014) Efficacy of methylprednisolone on pain, fatigue, and appetite loss in patients with advanced cancer using opioids: a randomized, placebo-controlled, double-blind trial. J Clin Oncol 32:3221-3228

28. Aaronson NK, Ahmedzai S, Bergman B, Bullinger M, Cull A, Duez NJ, Filiberti A, Flechtner H, Fleishman SB, de Haes JC et al (1993) The European Organization for Research and Treatment of Cancer QLQ-C30: a quality-of-life instrument for use in international clinical trials in oncology. J Natl Cancer Inst 85:365-376

29. Osoba D, Rodrigues G, Myles J, Zee B, Pater J (1998) Interpreting the significance of changes in health-related quality-of-life scores. J Clin Oncol 16:139-144

30. Buysse DJ, Reynolds CF 3rd, Monk TH, Berman SR, Kupfer DJ (1989) The pittsburgh sleep quality index: a new instrument for psychiatric practice and research. Psychiatry Res 28:193-213

31. Folstein MF, Folstein SE, McHugh PR (1975) Mini-mental state. A practical method for grading the cognitive state of patients for the clinician. J Psychiatr Res 12:189-198

32. Karnofsky DA, Abelmann WH, Craver LF, Burchenal JH (1948) The use of nitrogen mustards in the palliative treatment of carcinoma. Cancer 1:23

33. Caraceni A, Hanks G, Kaasa S, Bennett MI, Brunelli C, Cherny N, Dale O, De Conno F, Fallon M, Hanna M, Haugen DF, Juhl G, King S, Klepstad P, Laugsand EA, Maltoni M, Mercadante S, Nabal M, Pigni A, Radbruch L, Reid C, Sjogren P, Stone PC, Tassinari D, Zeppetella G (2012) Use of opioid analgesics in the treatment of cancer pain: evidence-based recommendations from the EAPC. Lancet Oncol 13:e58-e68

34. Yennurajalingam S, Chisholm G, Palla SL, Holmes H, Reuben JM, Bruera E (2013) Self-reported sleep disturbance in patients with advanced cancer: frequency, intensity, and factors associated with 
response to outpatient supportive care consultation - a preliminary report. Palliative \& supportive care 13:135-143

35. Teunissen SC, Wesker W, Kruitwagen C, de Haes HC, Voest EE, de Graeff A (2007) Symptom prevalence in patients with incurable cancer: a systematic review. J Pain Symptom Manag 34:94-104

36. Chrousos GA, Kattah JC, Beck RW, Cleary PA (1993) Side effects of glucocorticoid treatment. Experience of the Optic Neuritis Treatment Trial JAMA 269:2110-2112

37. Lundstrom S, Furst CJ, Friedrichsen M, Strang P (2009) The existential impact of starting corticosteroid treatment as symptom control in advanced metastatic cancer. Palliat Med 23:165-170

38. Yennurajalingam S, Tayjasanant S, Balachandran D, Padhye NS, Williams JL, Liu DD, Frisbee-Hume S, Bruera E (2016) Association between daytime activity, fatigue, sleep, anxiety, depression, and symptom burden in advanced cancer patients: a preliminary report. J Palliat Med 19:849-856

39. George GC, Iwuanyanwu EC, Anderson KO, Yusuf A, Zinner RG, Piha-Paul SA, Tsimberidou AM, Naing A, Fu S, Janku F, Subbiah V, Cleeland CS, Mendoza TR, Hong DS (2016) Sleep quality and its association with fatigue, symptom burden, and mood in patients with advanced cancer in a clinic for early-phase oncology clinical trials. Cancer 122:3401-3409

40. Beernaert K, Pardon K, Van den Block L, Devroey D, De Laat M, Geboes K, Surmont V, Deliens L, Cohen J (2016) Palliative care needs at different phases in the illness trajectory: a survey study in patients with cancer Eur J Cancer Care (Engl) 25: 534-543
41. Hinz A, Mehnert A, Degi C, Reissmann DR, Schotte D, Schulte T (2017) The relationship between global and specific components of quality of life, assessed with the EORTC QLQ-C30 in a sample of 2019 cancer patients Eur J Cancer Care (Engl) 26

42. Innominato PF, Komarzynski S, Palesh OG, Dallmann R, Bjarnason GA, Giacchetti S, Ulusakarya A, Bouchahda M, Haydar M, Ballesta A, Karaboue A, Wreglesworth NI, Spiegel D, Levi FA (2018) Circadian rest-activity rhythm as an objective biomarker of patient-reported outcomes in patients with advanced cancer. Cancer medicine 7:4396-4405

43. Hjermstad MJ, Fayers PM, Bjordal K, Kaasa S (1998) Healthrelated quality of life in the general Norwegian population assessed by the European Organization for Research and Treatment of Cancer Core quality-of-life questionnaire: the $\mathrm{QLQ}=\mathrm{C} 30(+3)$. J Clin Oncol 16:1188-1196

44. Hui D, Glitza I, Chisholm G, Yennu S, Bruera E (2013) Attrition rates, reasons, and predictive factors in supportive care and palliative oncology clinical trials. Cancer 119:1098-1105

45. Broderick JE, Junghaenel DU, Schneider S, Pilosi JJ, Stone AA (2013) Pittsburgh and Epworth sleep scale items: accuracy of ratings across different reporting periods. Behav Sleep Med 11:173188

Publisher's note Springer Nature remains neutral with regard to jurisdictional claims in published maps and institutional affiliations.

\section{Affiliations}

\section{Gunnhild Jakobsen ${ }^{1,2}$ (D) - Morten Engstrøm ${ }^{3,4}$ - Marianne Jensen Hjermstad ${ }^{5,6,7}$ • Jan Henrik Rosland ${ }^{8,9} \cdot$ Nina Aass $^{5,10}$. Eva Albert ${ }^{11}$. Stein Kaasa ${ }^{1,6,7}$. Peter Fayers ${ }^{12}$ - Pål Klepstad ${ }^{13,14}$. Ørnulf Paulsen ${ }^{6,7,15}$}

1 Department of Clinical and Molecular Medicine, Faculty of Medicine and Health Sciences, NTNU Norwegian University of Science and Technology, Postbox 8905, N-7491 Trondheim, Norway

2 Cancer Clinic, St. Olavs Hospital, Trondheim University Hospital, Trondheim, Norway

3 Department of Neuromedicine and Movement Science, NTNU Norwegian University of Science and Technology, Trondheim, Norway

4 Department of Neurology and Clinical Neurophysiology, St. Olavs Hospital, Trondheim University Hospital, Trondheim, Norway

5 Regional Advisory Unit for Palliative Care, Department of Oncology, Oslo University Hospital, Oslo, Norway

6 European Palliative Care Research Centre, Department of Oncology, Oslo University Hospital, Oslo, Norway

7 Institute of Clinical Medicine, University of Oslo, Oslo, Norway
8 Department of Clinical Medicine, University of Bergen, Bergen, Norway

9 Sunniva Centre for Palliative Care, Haraldsplass Deaconess Hospital Bergen, Bergen, Norway

10 Institute of Clinical Medicine, Faculty of Medicine, University of Oslo, Oslo, Norway

11 Sørlandet Hospital Kristiansand, Kristiansand, Norway

12 Division of Applied Health Sciences, University of Aberdeen, Aberdeen, UK

13 Department of Anaesthesiology and Intensive Care Medicine, St. Olavs Hospital, Trondheim University Hospital,

Trondheim, Norway

14 Department of Circulation and Medical Imaging, Faculty of Medicine and Health Sciences, NTNU - Norwegian University of Science and Technology, Trondheim, Norway

15 Telemark Hospital Trust, Skien, Norway 